\title{
THE IMPACT OF MINERAL SEPARATION PROCEDURE ON THERMOLUMINESCENCE ANALYSIS OF NON-IRRADIATED DRIED FISH AND SHELLFISH
}

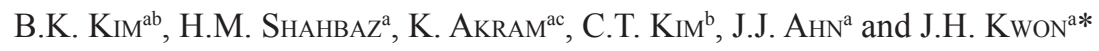 \\ ${ }^{\mathrm{a}}$ School of Food Science and Biotechnology, Kyungpook National University, 702-701 Daegu. South Korea \\ ${ }^{\mathrm{b}}$ Food Safety Research Institute, Nongshim Co. Ltd., 156-709 Seoul. South Korea \\ ${ }^{\mathrm{c}}$ Institute of Food Science and Nutrition, University of Sargodha, 40100 Sargodha. Pakistan
}

(Received: 13 December 2013; accepted: 21 May 2014)

\begin{abstract}
This study was aimed at evaluating the efficacy of different mineral separation procedures to validate the EN1788 (2001) European Union standard protocol for better identification of irradiated fish and shellfish. The silicate minerals were isolated with physical density separation method from two types of non-irradiated freeze-dried fish and shellfish that included Pacific saury (Cololabis saira), mackerel (Scomber japonicus), shrimp (Penaeidae metapenaeus), and mussel (Mytilus coruscus). Radiation-specific thermoluminescence (TL) peaks (glow curve 1) were observed between $150-250{ }^{\circ} \mathrm{C}$. The peaks are typical for the irradiated food; despite the samples being not irradiated. Apparently it showed that the isolated minerals were contaminated with organic materials such as bone, etc. Acid-hydrolysis digestion was employed to remove the possible contaminants. The minerals obtained through alternative pre-treatment showed no TL curves in radiation specific temperature range. Moreover, acid hydrolysis extraction resulted in producing higher mineral yields and lower background luminescence. Results were also confirmed by calculating TL ratios (glow curve 1/glow curve 2) to confirm the irradiation history of samples. Furthermore, different time and temperature treatments on TL intensity of irradiated standard quartz $\left(\mathrm{SiO}_{2}\right)$ minerals showed that the acid-hydrolysis can be adjusted to $50{ }^{\circ} \mathrm{C}$ and $3 \mathrm{~h}$ for better luminescence determinations.

Keywords: fish, shellfish, mineral separation, acid hydrolysis, thermoluminescence
\end{abstract}

Over 230 different food items in more than 55 countries have been permitted for irradiation (Farkas \& Mohácsi-Farkas, 2011; Shahbaz et al., 2013). Similarly, in Korea, 26 food categories have been approved for gamma-ray irradiation within the range of $0.15-10 \mathrm{kGy}$ (MFDS, 2010). The European Union (EU) has adopted the directives 1992/2/EC and 1999/3/ EC to standardize the rules concerning the treatment and trade of irradiated food in European countries for consumer acceptance and information. The directives include an obligation to label irradiated products and to apply standardized and validated methods for the detection of irradiated foods (European COMMISSION, 1999; FARKAS \& Mohácsi-FARKAS, 2011). The detection methods for irradiated foods were mainly established to monitor compliance to the labelling requirements on food irradiation. The detection techniques are usually classified as physical, chemical, and biological methods. Among the physical techniques, thermoluminescence (TL) uses heat to stimulate the trapped charge carriers resulting in the release of energy in the form of light. The energy released after heating at a specific temperature is associated with detectable luminescence. The origin of TL from irradiated foodstuff is mainly attributed to mineral contamination rather than the food material itself (SAnderson et al., 1989; Chauhan et al., 2009).

* To whom correspondence should be addressed. Phone: +82-53- 950 5775; fax: +82-53-950 6772; e-mail: jhkwon@knu.ac.kr 
Dried fish is one of the most important exported marine products in many countries around the world (DARvishi et al., 2012). Freeze-drying is a relatively new approach to prevent spoilage in fish by removing the moisture content necessary for the growth of bacteria and moulds (Bellagha et al., 2002; DuAn et al., 2004). In addition, many scientists have successfully applied ionizing radiation to extend the storage life and improve the quality of various dried fish (Kwon \& Byun, 1995; Venugopal et al., 1999; USDA, 2011). Similarly, radiation processing is also effective to reduce the pathogenic bacterial load in shellfish (CARmichael et al., 1994; IAEA, 2000).

Several researchers have used isolated silicate minerals to obtain reliable identification results (Autio \& Pinnioja, 1990; Schreiber et al., 1994; Sanderson et al., 1996; CruzZARAGOZA et al., 2012). Density separation is mostly used to obtain the required mineral fraction for TL analysis; however, the EN 1788 (EUROPEAN STANDARD, 2001) protocol suggests the use of acid hydrolysis pre-treatment as an alternative for fish and shellfish.

This study is aimed at comparing the efficacy of two different mineral isolation procedures (physical density separation and acid-hydrolysis extraction) for better TL identification characteristics in fish and shellfish samples; thereby validating the EN 1788 (2001) standard protocol. The study is based on the findings that the silicate minerals isolated through the physical density separation method may yield radiation-specific TL peaks (glow curve 1) in non-irradiated fish and shellfish samples. In addition, a study was conducted in order to evaluate the effect of different time and temperature conditions on the TL intensity of the irradiated standard quartz $\left(\mathrm{SiO}_{2}\right)$ minerals to find the optimal conditions for acidhydrolysis digestion.

\section{Materials and methods}

\subsection{Sample collection and freeze-drying}

In this study, four different fish and shellfish samples were investigated as depicted in the experiment flow chart (Fig. 1). Pacific saury (Cololabis saira), mackerel (Scomber japonicus), shrimp (Penaeidae metapenaeus), and mussel (Mytilus coruscus) were purchased from local markets in Seoul city, South Korea. All samples were frozen at a temperature of $-35{ }^{\circ} \mathrm{C}$ before freeze-drying treatment. Then whole samples were freeze-dried (Model SFDSF12, Suwon Freezing Engineering Co., Seoul, South Korea), packed in polyethylene bags, and stored in a refrigerator $\left(5 \pm 1^{\circ} \mathrm{C}\right)$.

\subsection{Minerals isolation}

Minerals were isolated from the whole freeze-dried samples using two different techniques, density separation and acid hydrolysis, described in the official European Union standard protocol EN 1788 (2001). The isolation of minerals was conducted under low light conditions.

1.2.1. Density separation. The samples were dissected into small pieces and rinsed with distilled water described in the standard protocol EN 1788 (2001). Briefly, sodium polytungstate (density $2 \mathrm{~g} \mathrm{ml}^{-1}$ ) was used to physically remove the organic residues. Then isolated minerals were washed with deionised water, cleaned with $1 \mathrm{M} \mathrm{HCl}$, neutralized with ammonia and again washed with deionised water followed by acetone. The minerals were suspended in $5 \mathrm{ml}$ of acetone and the tubes were kept in an oven at $50{ }^{\circ} \mathrm{C}$ overnight to evaporate the acetone. The analysis was performed in triplicate. 


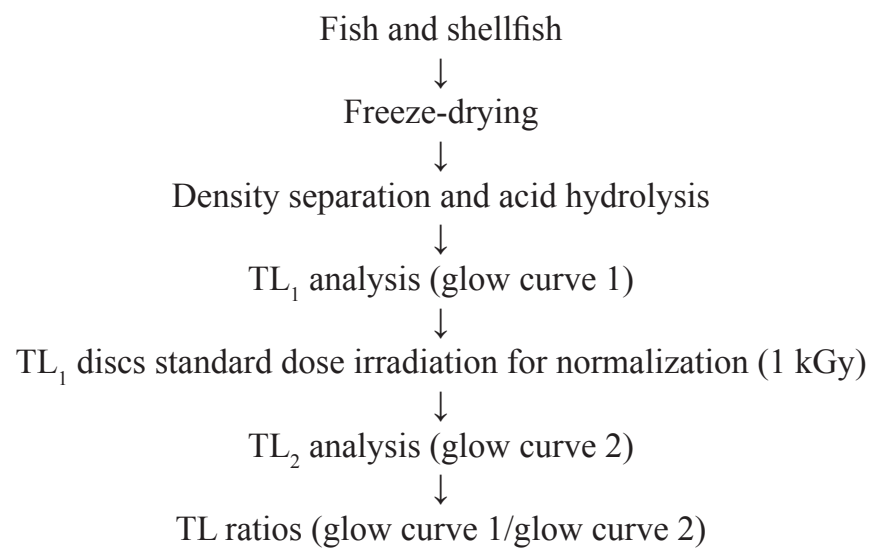

Fig. 1. Experiment flow chart

1.2.2. Acid hydrolysis. In contrast to the physical density separation method, acid hydrolysis involves the dissolution of samples while leaving the minerals. Twenty grams of each whole sample was placed in a round bottomed flask containing $200 \mathrm{ml}$ of $6 \mathrm{M}$ hydrochloric acid $(\mathrm{HCl})$. Continuous agitation was maintained at 150 r.p.m. for $3 \mathrm{~h}$ in a shaking incubator. Heating was provided up to $50{ }^{\circ} \mathrm{C}$ for $20 \mathrm{~min}$. The digested samples were cooled and then diluted with deionised water followed by settling and decanting of the diluted acid solution leaving the minerals behind at the bottom of the beaker. Left over minerals were washed with deionised water several times and then rinsed in acetone. TL discs were prepared from the separated minerals (0.2 mg approximately) of each sample for TL analysis (EuROPEAN StANDARD, 2001).

Quartz is a natural dosimeter that can be used to test the irradiation history of materials including foodstuffs (Preusser et al., 2009). The effect of different time and temperature conditions on the TL intensity of the irradiated standard quartz $\left(\mathrm{SiO}_{2}\right)$ minerals was evaluated. The standard quartz minerals were obtained from RISØ DTU, Denmark.

\subsection{Thermoluminescence analysis}

European Union standard protocol EN 1788 (2001) was followed for the sample preparation and TL analysis. TL measurements (glow curve 1) of the isolated minerals from each sample were done with a TLD system (Harshaw TLD-3500, Thermo Scientific, Waltham, MA, USA) under continuous nitrogen flush $(2 \mathrm{ml} \mathrm{min}-1)$ at a linear heating rate of $5{ }^{\circ} \mathrm{C} \mathrm{sec}^{-1}$. The temperature during heating was raised from $50{ }^{\circ} \mathrm{C}$ to $300{ }^{\circ} \mathrm{C}$ and the TL signals were calculated as the sum of the photon counts in the specific range of $150{ }^{\circ} \mathrm{C}$ to $250{ }^{\circ} \mathrm{C}$.

TL discs were carried to the Korean Atomic Energy Research Institute (Jeongeup, Korea) and exposed to a defined radiation dose of $1 \mathrm{kGy}$ using a Cobalt-60 gamma-ray source (AECL, IR-79, MDS Nordion International Co. Ltd., Ottawa, Ontario, Canada). The irradiation process was done at room temperature with a dose rate of $1.5 \mathrm{kGy} \mathrm{h}^{-1}$. The absorbed doses $( \pm 5.6 \%)$ were calibrated by alanine dosimeters with a $5 \mathrm{~mm}$ diameter (Bruker Instruments, Rheinstetten, Germany), in which the free-radical signals were determined with a Bruker EMS 104 EPR analyzer (Bruker Instruments, Rheinstetten, Germany). The discs were pre-heated for about $16 \mathrm{~h}$ in an oven at $50{ }^{\circ} \mathrm{C}$. The second glow curves $\left(\mathrm{TL}_{2}\right)$ were 
registered with the same TL reader under identical measuring conditions. The TL ratios (glow curve 1/glow curve 2) were calculated to verify the TL results (EuropeAn STANDARD, 2001). Microsoft excel (Microsoft Office 2010 version) and Origin 6 software were used for the data analysis and presentation.

\section{Results and discussion}

\subsection{TL characteristics of silicate minerals isolated through density separation method}

Figure 2 shows the TL glow curves of the minerals isolated from non-irradiated freeze-dried fish and shellfish samples through density separation. The TL glow curves were measured between the temperature range of $50-300{ }^{\circ} \mathrm{C}$. TL glow curves of minerals extracted from non-irradiated shrimp and mussel were absent in the specific temperature range of 150-250 ${ }^{\circ} \mathrm{C}$. However, unexpected results were detected in the case of minerals separated from nonirradiated Pacific saury and mackerel samples. Glow curve 1 peaks were obtained in the specific temperature range of $150-250^{\circ} \mathrm{C}$ despite the samples were not irradiated. Generally, the silicate minerals trapped in the intestines or shells (biogenic exoskeletons) of shellfish are considered responsible for the TL analysis results (Autio \& PinniojA, 1990). However, there is experimental evidence that carbonate minerals (calcite) from the shell can be used for the identification of such kinds of food (CARmichael et al., 1994; Cruz-Zaragoza et al., 2012). Upon irradiation, calcite $\left(\mathrm{CaCO}_{3}\right)$ produces TL glow curve peaks at 100,270 , and $340{ }^{\circ} \mathrm{C}$ (Duller et al., 2009).
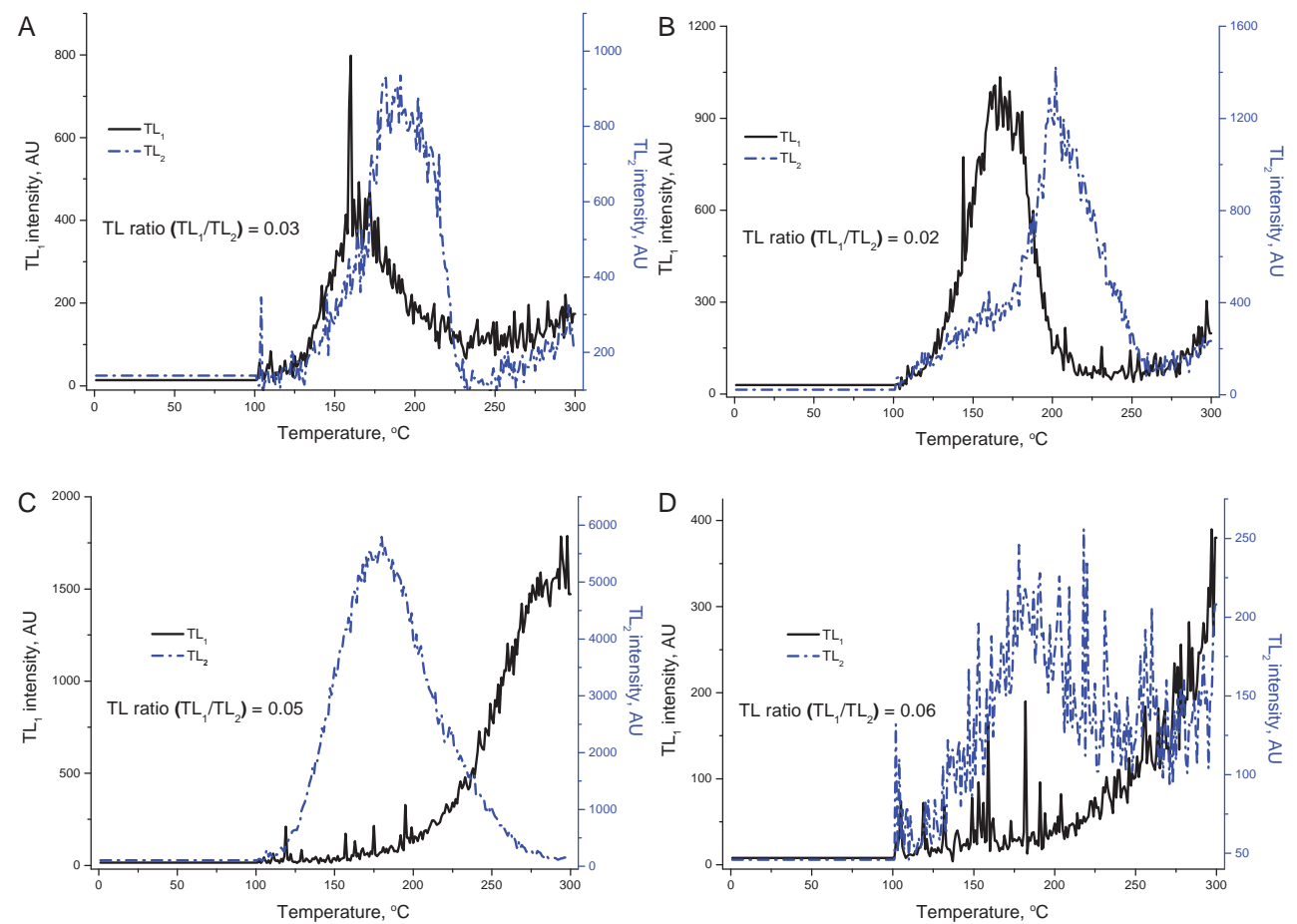

Fig. 2. $\mathrm{TL}_{1}$ and $\mathrm{TL}_{2}$ glow curves and $\mathrm{TL}$ ratio $\left(\mathrm{TL}_{1} / \mathrm{TL}_{2}\right)$ of minerals separated from non-irradiated fish and shellfish using density separation method. (A: Pacific saury; B: Mackerel; C: Mussel; D: Shrimp) 
Our findings are in agreement with KYUNG and co-workers (2012) who reported the TL glow curve of the minerals extracted (density separation) from non-irradiated dried mussel samples with maximum peak at $225^{\circ} \mathrm{C}$ (false-positive). In addition, the minerals separated from irradiated ( $5 \mathrm{kGy}$ ) dried shrimps and mussels by density separation showed very high intensity of TL glow peak before $200^{\circ} \mathrm{C}$. The comparison of peaks showed that non-irradiated samples produced TL glow curves of low intensity (KYUNG et al., 2012).

SEKIGUCHI and co-workers (2009) found the glow curve 1 between temperatures $146.5^{\circ} \mathrm{C}$ and $175.4{ }^{\circ} \mathrm{C}$ from minerals separated from non-irradiated seasoning mixes (dried bonito fish). Therefore, it is concluded that false-positive glow curves may be obtained from the seasoning mixes because of luminescence from some components other than silicate minerals. The present results showed that the mineral samples were probably contaminated with organic materials such as calcite minerals from bone. To overcome this problem, acid hydrolysis was performed to remove the possible contaminants other than silicate minerals.

\subsection{TL characteristics of silicate minerals isolated through acid hydrolysis method}

As shown in Fig. 3, the silicate minerals isolated through the acid hydrolysis digestion provided improved TL results. TL glow curve 1 disappeared in the radiation-specific temperature range 150 to $250{ }^{\circ} \mathrm{C}$ in Pacific saury and mackerel samples. Correspondingly, improved TL results were obtained in the case of shrimp and mussel samples (Fig. 3). KYUNG and co-workers (2012) also successfully addressed the false-positive TL glow curve peaks using acid hydrolysis from non-irradiated dried mussel samples. D'OCA and BARTOLOTTA (2010) found that acid hydrolysis was effective in characterizing the irradiation status of crustaceans. Previously, Carmichael and SAnderson (2000) compared the acid hydrolysis extraction to conventional physical dissection method for TL detection of six species of irradiated shellfish. The acid hydrolysis method was able to provide better discrimination between the irradiated and non-irradiated samples. CHEN and co-workers (2011) also reported the successful use of acid hydrolysis pre-treatment to separate silicate minerals from frozen prawns for the TL analysis. AHN and co-workers (2013) reported the use of different acid treatments of shellfish exoskeletons (Corbicula \& Melanian snail) to identify their irradiation status. Acid-hydrolysis treatment dissolves the calcite minerals from the bone part leaving the fraction enriched in silicate minerals. In addition, acid hydrolysis provides a promising alternative while saving time and complexity involved in the physical extraction procedures (CARmichael \& SAnderson, 2000; Kyung et al., 2012).

EN 1788 (2001) standard protocol recommends the confirmation of $\mathrm{TL}_{1}$ results by determining the $\mathrm{TL}$ ratio $\left(\mathrm{TL}_{1} / \mathrm{TL}_{2}\right)$. The reliability of $\mathrm{TL}_{1}$ glow curve characteristics was confirmed by calculating the TL ratio $(<0.1)$ shown in Figures 2 and 3 . The TL ratios of the minerals separated from the non-irradiated samples using the acid hydrolysis technique yielded similar results $(<0.1)$ to the density separation method. In addition, the $\mathrm{TL}_{2}$ glow curve peaks from irradiated silicate minerals were shifted to higher temperatures. These values provided conclusive information to confirm the irradiation history of samples. AHN and co-workers (2013) also found that TL ratios were $<0.1$ for non-irradiated shellfish samples. KYUNG and co-workers (2012) reported similar TL ratios $(<0.1)$ of the minerals separated from the non-irradiated dried shrimp and mussel samples regardless of mineral separation procedure. 

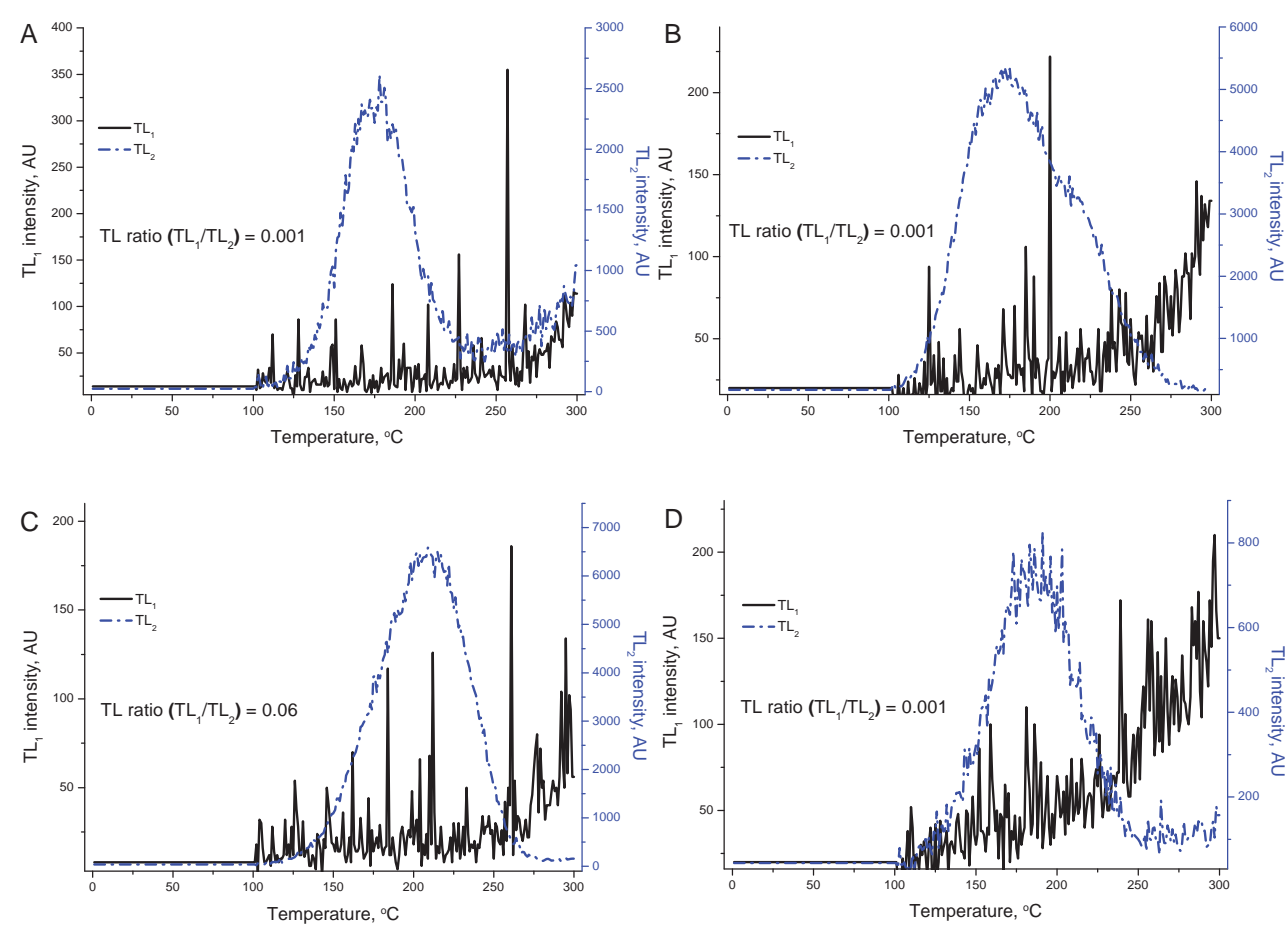

Fig. 3. $\mathrm{TL}_{1}$ and $\mathrm{TL}_{2}$ glow curves and $\mathrm{TL}$ ratio $\left(\mathrm{TL}_{1} / \mathrm{TL}_{2}\right)$ of minerals separated from non-irradiated fish and shellfish using acid hydrolysis method (A: Pacific saury; B: Mackerel; C: Mussel; D: Shrimp)

Quartz has the potential to store energy as a latent signal within its crystal lattice when exposed to ionizing radiation. Quartz and feldspar minerals, etc., are considered to be responsible for the luminescence properties in irradiated materials (PreusSER et al., 2009). Figure 4 shows the effect of different temperature and time conditions on the TL intensity of irradiated standard quartz minerals during the acid hydrolysis pre-treatment. The data showed that the effect of temperature treatment was more pronounced on the luminescence properties of irradiated quartz material. An increase in the luminescence counts was recorded by decreasing the temperature from $130^{\circ} \mathrm{C}$ to $50^{\circ} \mathrm{C}$ at constant hydrolysis time of $3 \mathrm{~h}$. Similarly, luminescence counts in irradiated quartz minerals were slightly increased when hydrolysis time changed from 2 to $3 \mathrm{~h}$ at the fixed temperature of $50{ }^{\circ} \mathrm{C}$. Sekiguchi and co-workers (2009) also modified the reflux extraction procedure conditions to separate silicate minerals to identify seasoning mixes (dried fish) using TL method. Acid hydrolysis was carried out using $6 \mathrm{M} \mathrm{HCl}$ and temperature was maintained at $120-130{ }^{\circ} \mathrm{C}$ for $3 \mathrm{~h}$ for better TL results. Previous studies have showed that thermal treatment may affect the luminescence properties (AHN et al., 2012). Recently, Kiм and co-workers (2014) reported a remarkable decrease in the TL intensity of seasoning samples after the spray drying treatment that involves high temperature $\left(150-175^{\circ} \mathrm{C}\right)$. Other scientists have reported that a high temperature environment may cause the fading of TL glow curves (KitAI \& FURUTA 2009; AHN et al., 2012). Based on the present results, it can be suggested that the optimal conditions for acid hydrolysis extraction can be adjusted at temperature of $50^{\circ} \mathrm{C}$ for $3 \mathrm{~h}$ for better luminescence counts. 

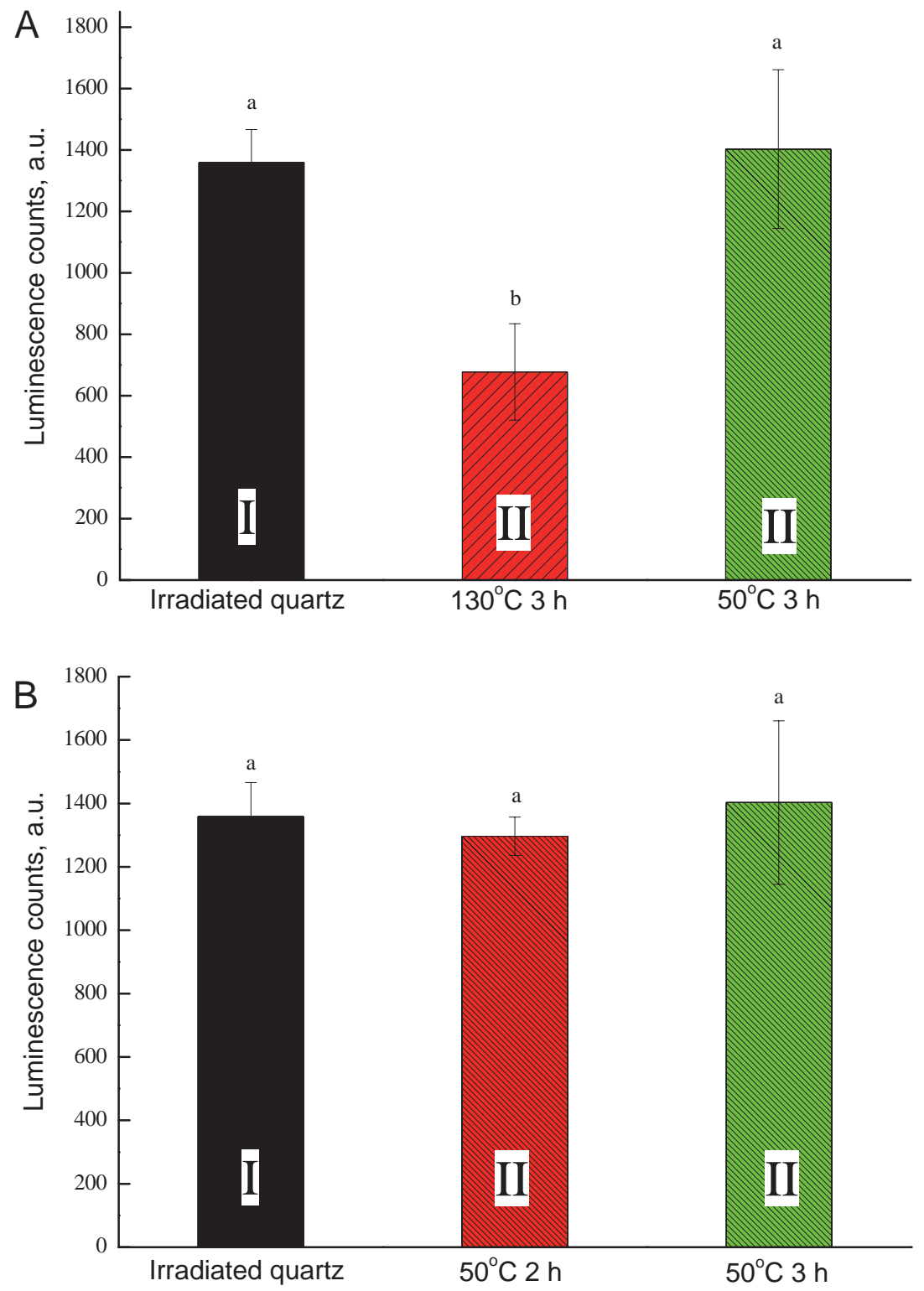

Fig. 4. Effect of temperature (A) and time (B) on TL intensity of 5 kGy-irradiated standard quartz mineral during acid hydrolysis pre-treatment (I: untreated; II: acid hydrolysis)

\section{Conclusions}

False-positive results could be possible with the physical density separation of silicate minerals for TL analysis of dried fish and shellfish samples. The current study reports the occurrence of TL glow curve 1 peaks in the specific temperature range of $150-250{ }^{\circ} \mathrm{C}$ for 
non-irradiated Pacific saury and mackerel samples. However, the $\mathrm{TL}_{1}$ glow curve peaks disappeared when acid digestion step was used to isolate the silicate minerals. Acid hydrolysis extraction helps to remove the possible contaminants other than silicate minerals. Therefore, improved identification of fish and shellfish could be achieved by the acid hydrolysis pretreatment by producing higher amount of silicate minerals and lower background luminescence. The optimization study on the acid extraction conditions can be helpful to get the best luminescence counts based on acid hydrolysis digestion.

This work was supported by the National Research Foundation of Korea (NRF) grant funded by the Korean government (No. 2013R1A1A4A03006993).

\section{References}

Ahn, J.J., Akram, K., JeOng, M.S., KwAK, J.Y. \& KwON, J.H. (2013): Identification of irradiated shellfish using wellcharacterized thermoluminescence properties of biogenic minerals present in the exoskeleton. Food Anal. Methods, 6, 1345-1352.

Ahn, J.J., Akram, K., JeOng, M.S., KwaK, J.Y., Jang, Y.D. \& Kwon, J.H. (2012): Radiation-induced thermoluminescence characteristics of feldspar following different heat and microwave treatments. J. Lumin., 132, 1964-1968.

Autio, T. \& Pinnioja, S. (1990): Identification of irradiated foods by thermoluminescence of the contaminating minerals. Eur. Food Res. Technol., 191, 177-180.

Bellagha, S., Amami, E., Farhat, A. \& Kechaou, N. (2002): Drying kinetics and characteristic drying curve of lightly salted Sardine (Sardinella aurita). Dry Technol., 20, 1527-1538.

Carmichael, L.A., Sanderson, D.C.W. \& Ni Riain, S. (1994): Thermoluminescence measurement of calcite shells. Radiat. Meas., 23, 455-463.

Carmichael, L.A. \& SAnderson, D.C.W. (2000): The use of acid hydrolysis for extracting minerals from shellfish for thermoluminescence detection of irradiation. Food Chem., 68, 233-238

Chauhan, S.K., Kumar, R., Nadanasabapathy, S. \& Bawa, A.S. (2009): Detection methods for irradiated foods. Compr. Rev. Food Sci. F., 8, 4-16.

Chen, S., Morita, Y., Saito, K., Kameya, H., Nakajima, M. \& Todoriki, S.J. (2011): Identification of irradiated prawn (Penaeus monodon) using thermoluminescence and 2-alkylcyclobutanone analyses. J. Agric. Food Chem., 59, 78-84.

Cruz-Zaragoza, E., Marcazzó, J., Monaca, S.D., Boniglia, C., Gargiulo, R. \& Bortolin, E. (2012): Thermoluminescence analysis of irradiated oyster shells. Appl. Radiat. Isotopes, 71, 18-22.

Darvishi, H., Azadbakht, M., Rezaeiasl, A. \& Farhang, A. (2012): Drying characteristics of sardine fish dried with microwave heating. J. Saudi Soc. Agric. Sci., 12, 121-127.

D’Oca, M.C. \& Bartolotta, A. (2010): The identification of irradiated crustaceans and evaluation of the dose by thermoluminescence: Intercomparison between two methods for extracting minerals. Food Res. Int., 43, 1255-1259.

DuAn, Z.H., Zhang, M. \& TANG, J. (2004): Thin layer hot-air drying of bighead carp. Fisheries Sci., 23, $29-32$.

Duller, G.A.T., Penkman, K.E.H. \& Wintle, A.G. (2009): Assessing the potential for using biogenic calcites as dosimeters for luminescence dating. Radiat. Meas., 44, 429-433.

EUROPEAN STANDARD (2001): Foodstuffs - Detection of irradiated food from which silicate minerals can be isolated, method by thermoluminescence. No. EN 1788, European Committee for Standardization, Brussels, Belgium.

European Commission (1999): Directive 1999/2/EC of the European Parliament and of the Council of 22 February 1999 on the approximation of the laws of the Member States concerning foods and food ingredients treated with ionising radiation. Official Journal of the European Communities, Series L, 66, 16-24.

FARKAS, J. \& MohÁcsi-FARKas, Cs. (2011): History and future of food irradiation. Trends Food Sci. Tech., 22, 121126.

IAEA (2000): Irradiation of fish, shellfish and frog-legs - a compilation of technical data for its authorization and control. IAEA-TECDOC-1158. Vienna, Austria. 
Kiм, B.K., Ahn, J.J., Shahbaz, H.M., Kıм, С.T. \& Kwon, J.H. (2014): Effect of drying treatment on physical identification characteristics of irradiated seasonings. Food Anal. Method., 7, 268-275.

KitAI, S. \& FuRUTA, M. (2009): Change in thermoluminescence of irradiated paprika powder during storage under various temperature and humidity conditions. Radiat. Phys. Chem., 78, 703-705.

Kwon, J.H. \& BYun, M.W. (1995): Gamma irradiation combined with improved packaging for preserving and improving the quality of dried fish. Radiat. Phys. Chem., 46, 725-729.

Kwon, J.H., Ahn, J.J., Akram, K., Son, I.J. \& LeE, S.O. (2013): Characterization of radiation-induced luminescence properties and free radicals for the identification of different gamma-irradiated teas. Anal. Bioanal. Chem., 405, 4225-4234.

Kyung, H.K., Ahn, J.J., Akram, K. \& Kwon, J.H. (2012): Thermoluminescence analysis of irradiated dried sea foods using different methods of mineral separation. Radiat. Phys. Chem., 81, 1224-1226.

MFDS (2010): Food Code: The Ministry of Food \& Drug Safety. Seoul, Korea. p. 2-1-9

Preusser, F., Chithambo, M.L., Götte, T., Martini, M., Ramseyer, K., Sendezera, E.J., Susino, G.J. \& Wintle, A.G. (2009): Quartz as a natural luminescence dosimeter. Earth-Sci. Rev., 97, 184-214.

Sanderson, D.C.W., Slater, W.C. \& CAirns, K.J. (1989): Thermoluminescence of foods: Origins and implication for detection irradiation. Radiat. Phys. Chem., 34, 915-924.

Sanderson, D.C.W., CARmichael, L.A., Spencer, J.Q. \& Naylor, J. (1996): Luminescence detection of shellfish. -in: McMurray, C.H. (Ed.), Detection methods for irradiated foods. Royal Society of Chemistry, Cambridge, UK, pp. 124-148.

Schreiber, G.A., Hoffmann, A., Helle, N. \& Bögl, K.W. (1994): Methods for routine control of irradiated food: determination of the irradiation status of shellifish by thermoluminescence analysis. Radiat. Phys. Chem., 43, 533-544.

SekIGUChI, M., NAKAgaWA, S. \& YUNOKI, S. (2009): Detection of irradiation history of seasoning mixes composed of dried fish and its extract - TL analysis and application considerations for mineral separation from foods. Bulletin TIRI, 4, 24-27.

Shahbaz H.M., Ahn, J.J., Akram, K. \& Kwon, J.H. (2013): Screening methods for the identification of irradiated foods. Current Res. Agri. Life Sci., 31, 1-10.

USDA/Agricultural Research Service (2011): New freeze-dry method good for processing fish. Sci. Daily, 59, 16. Available at http://www.sciencedaily.com/releases/2011/08/110801120345.htm (last accessed 28 April 2014)

Venugopal, V., Doke, S.N. \& Thomas, P. (1999): Radiation processing to improve the quality of fishery products. Crit. Rev. Food Sci. Nutr., 39, 391-440. 